INTERVENTIONAL CARDIOLOGY AND SURGERY

\title{
FRISC score for selection of patients for an early invasive treatment strategy in unstable coronary artery disease
}

\author{
B Lagerqvist, E Diderholm, B Lindahl, S Husted, F Kontny, E Ståhle, E Swahn, P Venge, A Siegbahn, \\ L Wallentin
}

Heart 2005;91:1047-1052. doi: 10.1136/hrt.2003.031369

See end of article for authors' affiliations .......................

Correspondence to: Dr Bo Lagerqvist, Department of Cardiology, University Hospital, S-751 85 Uppsala, Sweden; bo lagerqvisł@ucr.vas.lul.se

Accepted 26 August 2004
Objective: To develop a scoring system for risk stratification and evaluation of the effect of an early invasive strategy for treatment of unstable coronary artery disease (CAD).

Design: Retrospective analysis of a randomised study (FRISC II; fast revascularisation in instability in coronary disease).

Setting: 58 Scandinavian hospitals.

Patients: 2457 patients with unstable CAD from the FRISC II study.

Main outcome measures: One year rates of mortality and death/myocardial infarction (MI).

Methods: Patients were randomly assigned to an early invasive or a non-invasive strategy. From the noninvasive cohort independent variables of death or death/MI were identified.

Results: Seven factors, age $>70$ years, male sex, diabetes, previous MI, ST depression, and increased concentrations of troponins and markers of inflammation (interleukin 6 or $C$ reactive protein), were associated with an independent increased risk for death or death/MI. In patients with $\geqslant 5$ of these factors the invasive strategy reduced mortality from $15.4 \%$ (20 of 130) to $5.2 \%$ (7 of 134) (risk ratio (RR) 0.34 , $95 \%$ confidence interval $(\mathrm{Cl}) 0.15$ to $0.78, \mathrm{p}=0.006$ ). Death/ $\mathrm{Ml}$ was also reduced in patients with $3-4$ factors from $15.7 \%$ (80 of 511 ) to $10.8 \%$ (58 of 538) (RR 0.69, $95 \% \mathrm{Cl} 0.50$ to $0.94, \mathrm{p}=0.02$ ). Neither death nor death/MI was reduced in patients with 0-2 risk factors.

Conclusion: In unstable CAD, this scoring system based on factors independently associated with an adverse outcome can be used shortly after admission to the hospital for risk stratification and for selection of patients to an early invasive treatment strategy.
U nstable coronary artery disease (CAD)-unstable angina or non-ST elevation myocardial infarction (MI) — can be treated with an early invasive or a primarily non-invasive regimen. In the FRISC (fast revascularisation in instability in coronary disease) II, TACTICS (treat angina with Aggrastat and determine cost of therapy with an invasive or conservative strategy), and RITA (randomised intervention trial of unstable angina) III trials primary end point rates were reduced by the early invasive strategy. ${ }^{1-4}$ Subsequently, treatment recommendations have been changed and revascularisation procedures have increased substantially. However, not all patients with an episode of unstable CAD will benefit from this treatment, which is both expensive and associated with an inherent procedural risk. Thus, a means for selecting patients is needed. Several univariable risk indicators ${ }^{5-12}$ and multivariable risk scores have been used for risk stratification. ${ }^{13-16}$ However, a score focusing on treatment effect would be even more helpful in a clinical setting. ${ }^{17}{ }^{18}$ The objective of this study was to develop a scoring system (the FRISC score) consisting of clinically relevant and accessible factors that may be used to select patients for an early invasive strategy.

\section{METHODS \\ Patients}

In the FRISC II trial 2457 patients were randomly assigned to an invasive or a non-invasive regimen. ${ }^{1}$ Patients with unstable angina or non-ST elevation MI were eligible for the trial. Inclusion criteria were increasing or rest symptoms of cardiac ischaemia associated with either ST depression $\geqslant 0.1 \mathrm{mV}$ or $\mathrm{T}$ wave inversion $\geqslant 0.1 \mathrm{mV}$ in at least one lead or increased biochemical marker of myocardial damage.

The study complied with the Declaration of Helsinki and all local ethics committees approved the protocol.

\section{Randomised treatment}

The patients gave informed, written consent and were randomly assigned to an early invasive or early non-invasive strategy and to short or long term treatment with dalteparin. In the early invasive group coronary angiography and if appropriate revascularisation was to be performed within seven days. Revascularisation was recommended for all patients with $a \geqslant 70 \%$ diameter obstruction in any artery supplying a significant proportion of the myocardium. In the non-invasive group coronary angiography or revascularisation was recommended in case of recurrent angina and severe ischaemia during a pre-discharge exercise test or with (new) MI.

All patients received open label dalteparin for at least five days and always until a scheduled revascularisation procedure. Thereafter, the patients continued long term treatment with dalteparin or placebo. As long term dalteparin treatment had no significant effect on 12 months' outcome, the dalteparin and placebo groups have been combined in the present report.

Abbreviations: $C A D$, coronary artery disease; $C R P, C$ reactive protein; FRISC, fast revascularisation in instability in coronary disease; MI, myocardial infarction; RITA, randomised intervention trial of unstable angina; TACTICS, treat angina with Aggrastat and determine cost of therapy with an invasive or conservative strategy; TIMI, thrombolysis in myocardial infarction 


\section{Data collection}

Blood samples and biochemical analyses

At randomisation blood was collected in tubes containing EDTA or citrate and centrifuged at each site. The plasma was frozen in aliquots and stored at $-70^{\circ} \mathrm{C}$ until the analysis. Troponin $\mathrm{T}$, troponin $\mathrm{I}, \mathrm{C}$ reactive protein (CRP), fibrinogen, and interleukin 6 were measured at the department of clinical chemistry, Uppsala University, without knowledge of the patients' randomisation or clinical outcome. The total cholesterol concentration was analysed at the local hospital laboratory.

\section{Electrocardiography}

Twelve lead ECGs were obtained on admission and evaluated at a core laboratory, without knowledge of the patients' randomisation and clinical outcome. ST depression was considered present if the ST segment was horizontal or downsloping and at least $0.05 \mathrm{mV}$ below the isoelectric level. ${ }^{6}$

\section{Coronary angiography}

All coronary angiograms recorded within six months were evaluated locally and recorded in accordance with the American Heart Association committee report on CAD from 1975. ${ }^{19}$ Stenoses $\geqslant 50 \%$ were considered significant. Also, the occurrences of visible thrombus and TIMI (thrombolysis in myocardial infarction) flow were evaluated.

\section{Follow up and outcome events}

Patients were followed by outpatient visits for six months. The 12 month follow up was performed by telephone interview and, if appropriate, by evaluation of the patients' hospital record.

MI has been defined previously and was based on the presence of two of the conventional three criteria: typical chest pain, diagnostic ECG, or increased biochemical markers of myocardial damage twice the upper limit of normal. ${ }^{1}$ Only new Q waves were used for the diagnosis of MI in association with coronary artery bypass grafting. For percutaneous coronary interventions the biochemical criterion was three times the upper limit of normal.

\section{Baseline characteristics}

On the basis of previous experiences with risk stratification in stable and unstable CAD, variables at baseline that can predict a worse prognosis were selected (table 1). All variables were dichotomised. In this study patients older than 70 years had a higher incidence of death/MI, whereas in the group between $65-70$ years end point rates were similar to those below 65 years (data not shown). Therefore, for age, 70 years was chosen as the cut off level. For body mass index, cholesterol, and fibrinogen no clear cut off level could be identified and the median level was chosen as the cut off. Troponin T concentration, which was available for $95 \%$ of the population, or troponin I, for patients without available troponin $\mathrm{T}$, was used to define the occurrence of increased concentration of biochemical marker of myocardial damage. In previous reports from FRISC II, troponin $\mathrm{T} \geqslant 0.03 \mu \mathrm{g} / \mathrm{l}^{9}$ or troponin $\mathrm{I} \geqslant 0.03 \mu \mathrm{g} / \mathrm{l}^{20}$ identified patients with increased risk, which therefore were used as cut offs. Increased inflammatory activity was based on the interleukin 6 concentration or, if this was not available, the CRP concentration. Based on previous experiences, $5 \mathrm{ng} / \mathrm{l}$ and $10 \mathrm{mg} / \mathrm{l}$ were chosen as cut off concentrations for interleukin 6 and CRP, respectively. ${ }^{10-12}$ Interleukin 6 was most efficient for identifying patients with a large benefit from early revascularisation. ${ }^{12}$ However, this biochemical analysis has not yet reached clinical practice. In this study we therefore combined interleukin 6 and CRP into one variable with two alternatives.

\section{Statistical analysis}

Univariable associations between the risk indicators and outcome were evaluated by Pearson $\chi^{2}$ test. Variables achieving a significance level $<0.05$ were inserted in a forward stepwise logistic regression model and those independently $(p<0.05)$ associated with either the rate of death or death/MI were included as components of the FRISC score.

Each factor was given one point regardless of the magnitude of the odds ratio or whether the factor was present as an independent risk for both death and death/MI. Only patients with available data on all the factors in the FRISC score were included in the analyses. Information on vital status at 12 months was available for all of these patients but for three patients in the invasive group, information on MI could not be obtained.

The association between the FRISC score strata and outcome was assessed by $\chi^{2}$ test for trend (MantelHaenszel trend test).

We used the Hosmer-Lemeshow test to assess the goodness of fit of the logistic regression models. The predictive value of the FRISC score was evaluated with the C statistic-that is, the area under the receiver operating characteristic curve. All statistical analyses were performed with the SPSS 10.1 statistical program (SPSS Inc, Chicago, Illinois, USA).

Table 1 Mortality in relation to risk variables by univariable and multivariable analyses* in the non-invasive cohort

\begin{tabular}{|c|c|c|c|c|c|c|c|}
\hline \multirow[b]{2}{*}{ Risk variable } & \multirow{2}{*}{$\begin{array}{l}\text { Fulfilling risk variable } \\
\text { criteria }\end{array}$} & \multicolumn{2}{|c|}{$\begin{array}{l}\text { Mortality risk } \\
\text { variable }\end{array}$} & \multicolumn{2}{|l|}{ Univariable analyses } & \multicolumn{2}{|c|}{ Multivariable analyses $(n=1157$ ) } \\
\hline & & Present & Absent & OR $(95 \% \mathrm{Cl})$ & p Value & OR $(95 \% \mathrm{Cl})$ & p Value \\
\hline Age $\geqslant 70$ years & $382 / 1235$ (30.9\%) & $6.8 \%$ & $2.6 \%$ & 2.76 (1.54 to 4.93$)$ & 0.001 & $2.18(1.17$ to 4.07$)$ & 0.014 \\
\hline Male sex & $834 / 1235$ (67.5\%) & $4.2 \%$ & $3.2 \%$ & 1.31 (0.68 to 2.50$)$ & 0.42 & NA & NA \\
\hline $\mathrm{BMI} \geqslant 26 \mathrm{~kg} / \mathrm{m}^{2} \dagger$ & $671 / 1218(54.2 \%)$ & $3.7 \%$ & $3.8 \%$ & $0.97(0.54$ to 1.75$)$ & 0.92 & NA & NA \\
\hline Cholesterol $\geqslant 5.8 \mathrm{mmol} / \mathrm{l} \dagger$ & $588 / 1194(49.2 \%)$ & $3.1 \%$ & $4.5 \%$ & $0.88(0.48$ to 1.60$)$ & 0.62 & NA & NA \\
\hline Hypertension & $377 / 1235(30.5 \%)$ & $6.4 \%$ & $2.8 \%$ & 2.36 (1.32 to 4.22$)$ & 0.009 & NA & 0.15 \\
\hline Diabetes & $144 / 1235$ (11.7\%) & $12.5 \%$ & $2.7 \%$ & 5.05 (2.74 to 9.32$)$ & $<0.001$ & 4.18 (2.17 to 8.04$)$ & $<0.001$ \\
\hline Previous Ml & $268 / 1235$ (21.7\%) & $6.7 \%$ & $3.1 \%$ & $2.25(1.23$ to 4.10$)$ & 0.008 & NA & 0.055 \\
\hline Angina pectoris $>3$ months & $428 / 1235$ (34.7\%) & $5.6 \%$ & $3.0 \%$ & 1.94 (1.09 to 3.46$)$ & 0.025 & NA & 0.18 \\
\hline ST depression at entry & $572 / 1215(47.1 \%)$ & $5.8 \%$ & $2.0 \%$ & 2.96 (1.54 to 5.69$)$ & 0.001 & $2.54(1.29$ to 5.00$)$ & 0.007 \\
\hline Increased troponin $\ddagger$ & $828 / 1188(69.7 \%)$ & $4.5 \%$ & $2.5 \%$ & $1.82(0.87$ to 3.82$)$ & 0.11 & NA & NA \\
\hline Fibrinogen $\geqslant 3.8 \mathrm{~g} / \mathrm{l} \dagger$ & $617 / 1169$ (52.8\%) & $4.9 \%$ & $2.7 \%$ & $1.83(0.97$ to 3.44$)$ & 0.061 & NA & NA \\
\hline $\mathrm{IL}-6 \geqslant 5$ or $\mathrm{CRP} \geqslant 10 \S$ & $326 / 1176(27.7 \%)$ & $8.3 \%$ & $2.4 \%$ & 3.75 (2.07 to 6.78$)$ & $<0.001$ & $3.26(1.75$ to 6.09$)$ & $<0.001$ \\
\hline
\end{tabular}

*Hosmer-Lemeshow test, $\chi^{2}=2.8, \mathrm{p}=0.73$; †median value; †troponin $\mathrm{T} \geqslant 0.03 \mu \mathrm{g} / \mathrm{l}$ or, if not available, troponin I $\geqslant 0.03 \mu \mathrm{g} / \mathrm{l}$; §interleukin 6 (IL-6) $\geqslant 5 \mathrm{ng} / \mathrm{l} \mathrm{or,} \mathrm{if}$ not available, $C$ reactive protein (CRP) $\geqslant 10 \mathrm{mg} / \mathrm{l}$.

$\mathrm{BMI}$, body mass index; Cl, confidence interval; MI, myocardial infarction; NA, not applicable; OR, odds ratio. 
Table 2 Death or MI in relation to risk variables, univariable and multivariable analyses* in the non-invasive cohort

\begin{tabular}{|c|c|c|c|c|c|c|c|}
\hline \multirow[b]{2}{*}{ Risk variable } & \multirow{2}{*}{$\begin{array}{l}\text { Fulfilling risk variable } \\
\text { criteria }\end{array}$} & \multicolumn{2}{|c|}{$\begin{array}{l}\text { Death/MI (\%) risk } \\
\text { variable }\end{array}$} & \multicolumn{2}{|l|}{ Univariable analyses } & \multicolumn{2}{|c|}{ Multivariable analyses $(n=1168)$} \\
\hline & & Present & Absent & OR $(95 \% \mathrm{Cl})$ & $p$ value & OR $(95 \% \mathrm{Cl})$ & $\mathrm{p}$ Value \\
\hline Age $\geqslant 70$ years & $382 / 1235(30.9 \%)$ & 21.7 & 10.7 & 2.32 (1.68 to 3.22 ) & $<0.001$ & 1.95 (1.37 to 2.78$)$ & $<0.001$ \\
\hline Male sex & $834 / 1235(67.5 \%)$ & 15.8 & 10.5 & 1.61 (1.11 to 2.33 ) & 0.012 & $1.50(1.00$ to 2.25$)$ & 0.049 \\
\hline$B M I \geqslant 26 \mathrm{~kg} / \mathrm{m}^{2} \dagger$ & $671 / 1218(54.2 \%)$ & 13.4 & 14.6 & $0.90(0.65$ to 1.25$)$ & 0.54 & NA & NA \\
\hline Cholesterol $\geqslant 5.8 \mathrm{mmol} / \mathrm{l} \dagger$ & $588 / 1194(49.2 \%)$ & 12.4 & 15.3 & $0.92(0.66$ to 1.28$)$ & 0.62 & NA & \\
\hline Hypertension & $377 / 1235(30.5 \%)$ & 18.0 & 12.4 & $1.56(1.12$ to 2.18$)$ & 0.009 & NA & 0.31 \\
\hline Diabetes & $144 / 1235(11.7 \%)$ & 29.9 & 12.0 & $3.12(2.09$ to 4.66$)$ & $<0.001$ & $3.14(2.05$ to 4.81$)$ & $<0.001$ \\
\hline Previous MI & $268 / 1235(21.7 \%)$ & 23.5 & 11.5 & 2.37 (1.68 to 3.34 ) & $<0.001$ & 2.00 (1.38 to 2.89$)$ & $<0.001$ \\
\hline Angina pectoris $>3$ months & $428 / 1235(34.7 \%)$ & 19.4 & 11.3 & 1.89 (1.37 to 2.62$)$ & $<0.001$ & NA & 0.07 \\
\hline ST depression at entry & $572 / 1215(47.1 \%)$ & 18.2 & 10.4 & $1.91(1.37$ to 2.66$)$ & $<0.001$ & $1.72(1.21$ to 2.45$)$ & 0.003 \\
\hline Increased troponin $\ddagger$ & $828 / 1188(69.7 \%)$ & 16.7 & 8.3 & 2.20 (1. .45 to 3.34$)$ & $<0.001$ & $1.84(1.18$ to 2.86$)$ & 0.007 \\
\hline Fibrinogen $\geqslant 3.8 \mathrm{~g} / \mathrm{l} \dagger$ & $617 / 1169(52.8 \%)$ & 16.0 & 12.1 & 1.38 (0.99 to 1.93 ) & 0.057 & NA & NA \\
\hline $\mathrm{IL}-6 \geqslant 5$ or $\mathrm{CRP} \geqslant 10 \S$ & $326 / 1176(27.7 \%)$ & 16.9 & 13.4 & $1.31(0.92$ to 1.86$)$ & 0.13 & NA & NA \\
\hline
\end{tabular}

\section{RESULTS}

\section{Prognostic variables in the non-invasive group}

In the non-invasive cohort $(\mathrm{n}=1235)$ one year mortality was $3.9 \%(\mathrm{n}=48)$ and the rate of death/MI $14.1 \%$ $(\mathrm{n}=174)$. In the univariable analyses, seven and eight variables were associated with an increased risk for mortality and death/MI, respectively, and were selected for the multivariable analyses. Age $\geqslant 70$ years, male sex, diabetes, previous MI, ST segment depression on admission, and increased concentrations of markers of myocardial damage and inflammation were independently related to mortality or the composite of death and MI. Thus, these seven variables were included in the final FRISC score model. Among these variables diabetes was the strongest independent predictor both for death and for death/MI. Increased inflammatory activity was, after diabetes, the second strongest predictor for mortality (tables 1 and 2 ).

The C statistics for the relation between the FRISC score and outcome were 0.77 for mortality and 0.70 for death/MI. Concerning different age cut offs, there were only small effects on the $\mathrm{C}$ statistics, ranging from $0.77-0.79$ for mortality and $0.68-0.70$ for death/MI when age cut offs varied in five year intervals from $60-80$ years. Also, when age was used as a continuous variable the $\mathrm{C}$ statistics were 0.79 for mortality and 0.70 for death/MI. As interleukin 6 is not yet easily available in clinical practice at many hospitals, we have also analysed the material for only CRP and disregarding interleukin 6 concentrations. The results are similar with

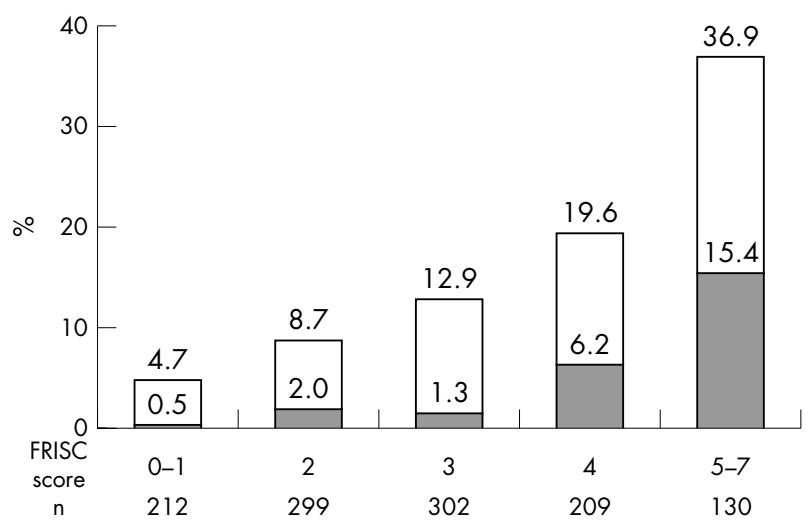

Figure 1 One year death (grey bars) and the composite of death and myocardial infarction (grey + white bars) in relation to FRISC score in the non-invasive cohort. By Mantel-Haenszel trend test, $\mathrm{p}<0.001$ for both death and death/myocardial infarction. a small decrease in $\mathrm{C}$ index to 0.76 for mortality and to 0.68 for the combined end point.

\section{FRISC score in relation to prognosis in the non- invasive group}

To obtain strata with adequate numbers of patients, groups with no or one risk variable and with $\geqslant 5$ risk variables were merged. There was a relation between the number of risk variables and the occurrence of death and the combination of death and MI ( $p<0.001$ for both). In the group with the highest FRISC score $(\geqslant 5)$ one year mortality was $15.4 \%$ (20 of 130) and the rate of death/MI was $36.9 \%$ (48 of 130). The corresponding numbers for the group with the lowest FRISC score (0-1) were $0.5 \%$ (one of 212 ) and $4.7 \%$ (10 of 212 ), respectively (fig 1 ).

\section{FRISC score in relation to angiographic findings in the invasive group}

In the invasive cohort coronary angiography was performed in $98 \%$ (1200 of 1222$)$ of the patients $(96 \%, 1176$ of 1222 , within seven days). Three vessel or left main disease occurred in more than $60 \%$ ( 80 of 129) of the patients with FRISC score $5-7$ and in $11 \%$ (20 of 179) of patients with FRISC score $0-1$ (fig 2). Also, the proportion of patients with TIMI III flow in all major vessels was related to the FRISC score (fig 3). However, no correlation with the occurrence of angiographically visible thrombus was observed.

\section{FRISC score in relation to effect of the invasive strategy}

To evaluate the treatment effect the patients were categorised into low, intermediate, or high risk based on the FRISC scores $0-2,3-4$, or 5-7. In the high risk group, which constituted $12 \%$ (264 of 2287) of the population, the invasive strategy reduced mortality from $15.4 \%$ (20 of 130 ) to $5.2 \%$ (seven of 134) (fig 4). The composite of death and MI was reduced in the intermediate and high risk groups, whereas in the low risk group no significant reduction was observed (fig 5).

\section{DISCUSSION}

In patients with unstable CAD the prognosis varies considerably depending on the clinical presentation. ST segment depression on the ECG and increased concentrations of biochemical markers of myocardial damage and inflammation are associated with a worse prognosis..$^{5-9} 1112$ Also, other factors such as increased age, hypertension, diabetes, and previous MI indicate a higher risk of future events. ${ }^{21} 22$ Although most studies have adjusted for other factors by multivariable analyses, the main analyses have focused on 


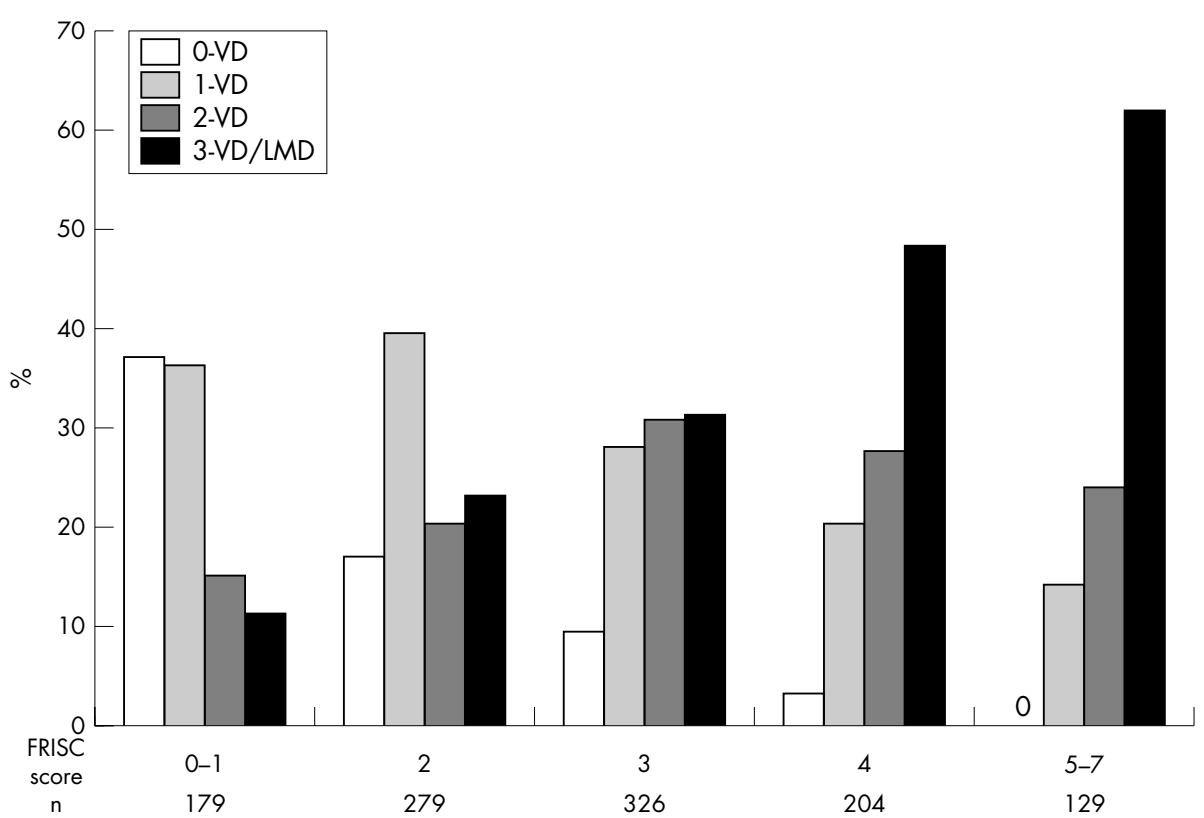

Figure 2 Distribution of severity of coronary artery disease at angiography in relation to FRISC score in the invasive cohort. 0 vessel disease $(\mathrm{VD})=$ no significant stenosis. LMD, left main disease.

just one of these factors. However, in a clinical setting, more comprehensive risk stratification is needed and more than one factor has to be considered. In the TIMI risk score seven clinical parameters were identified for risk stratification in unstable $\mathrm{CAD}$ on the triple end point death, MI, or urgent revascularisation. ${ }^{17}$ On the basis of the FRISC II study, in which the early invasive approach reduced both death and death/MI, we now present an alternative scoring system that may be used both for risk stratification and for selection of patients who would benefit most from early revascularisation.

\section{Is there a need for a risk score?}

Owing to the large number of and complex relation between risk factors it seems rational to produce a scoring system that, compared with a single risk indicator, further modulates the risk. Various scoring systems have been constructed for unstable CAD ..$^{13-18}$ However, the variables used in these studies vary considerably. A major problem when constructing a risk score is which parameters to choose and their relative importance. A risk score should be simple, contain

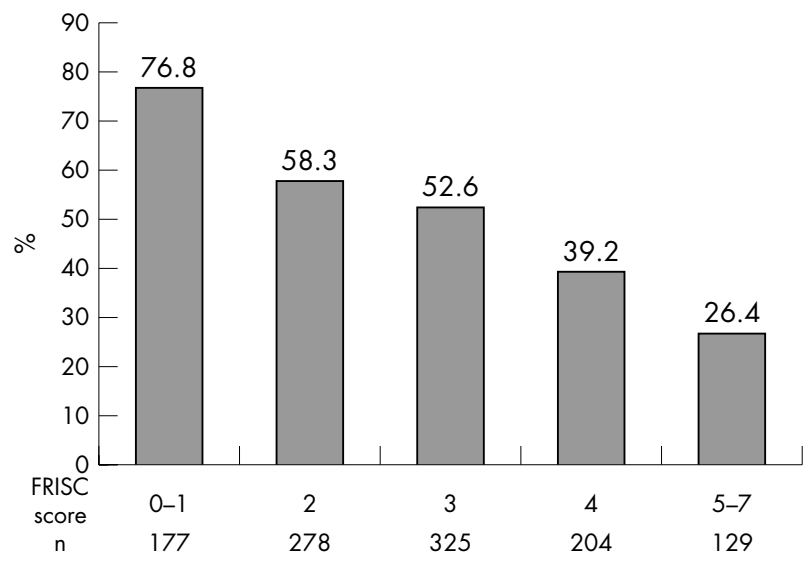

Figure 3 Number of patients with TIMI III flow in all major vessels in relation to FRISC score in the invasive cohort. By Mantel-Haenszel trend test, $\mathrm{p}<0.001$. readily available parameters, and preferably also identify patients who would benefit from a certain treatment.

\section{Choice of variables in the risk score}

When constructing a scoring system for risk stratification it seems logical to identify variables independently associated with outcome. In this study seven variables remained as independent predictors for death or death/MI and were included in the final model. A far more complex issue is how to construct a scoring system for evaluation of treatment effect, which was the primary objective. In this study we also used the multivariable risk evaluation to identify patients with the most beneficial treatment effect. Thus, we assumed that patients with the highest risk also had the largest reduction of events by the invasive strategy. In the univariable analyses of treatment effect this was confirmed (data not shown). Furthermore, the finding of a relation between the FRISC score and the occurrence of three vessel or left main disease in this study supports the correlation between subsequent risk and effect of invasive procedures, which are especially efficient if this angiographic finding is present. ${ }^{23}$

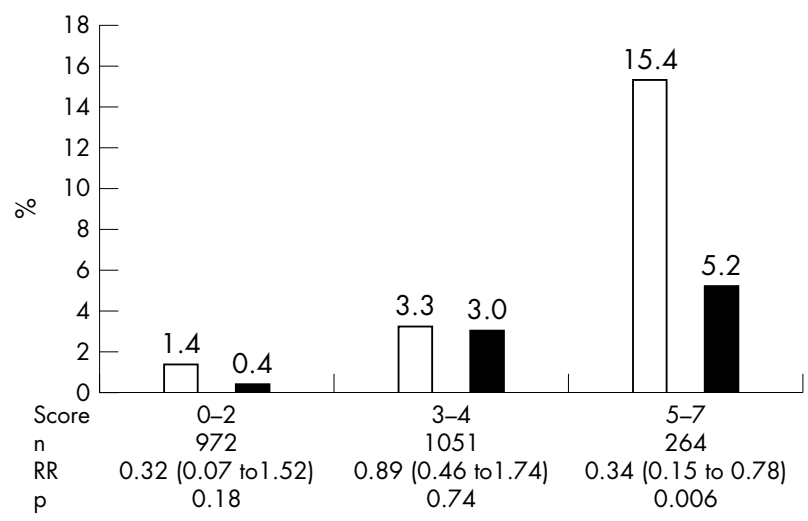

Figure 4 One year mortality in relation to treatment strategy and the FRISC score. White bars, non-invasive strategy; black bars, invasive strategy. Risk ratios (RR), confidence intervals, and $p$ values refer to the comparison between the invasive and non-invasive strategies. 


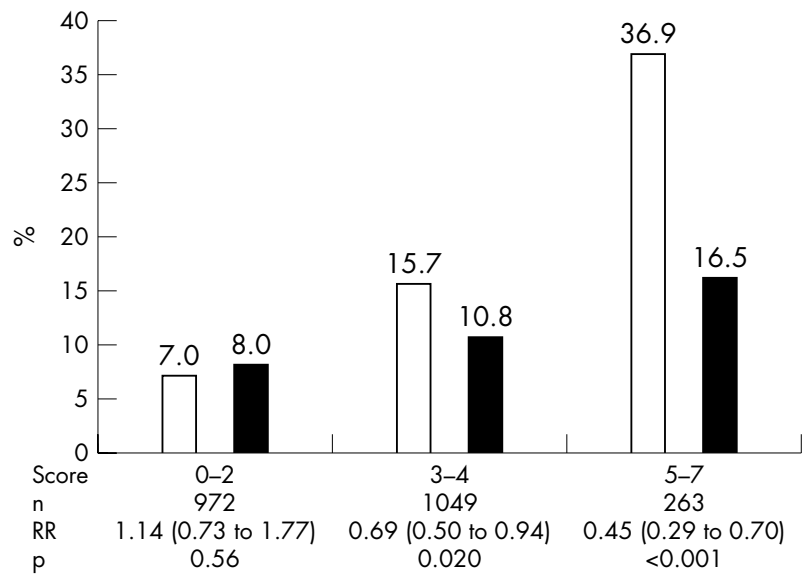

Figure 5 One year death or myocardial infarction in relation to treatment strategy and the FRISC score.

For six of the variables, there was a strong correlation with end point rates in the multivariable analyses $(p<0.001$ to $p=0.007)$. The significance was lower only for male sex $(p=0.049)$. However, the selection of this variable is also justified because of the interaction observed between sex and the effect of the early invasive strategy in both the FRISC II and RITA III studies, with a far more beneficial effect observed in the male population. ${ }^{424}$

The FRISC score appears to be well balanced with two demographic factors indicating the likelihood of CAD (age, sex), the major metabolic risk factor (diabetes), one factor indicating established CAD or reduced left ventricular function (previous MI), and three factors associated with the acute event: ischaemia (ST depression), myocardial damage or coronary thrombosis (troponins), and inflammation (interleukin 6 or CRP).

\section{Evaluation of prognosis and effect of the invasive strategy}

With this method a scoring system was developed in which the presence of an additional factor implied a higher risk. However, these retrospective findings need to be tested in prospective studies. More important, though, was that the FRISC score also could identify patients in whom early revascularisation was especially effective. The reduction in one year mortality was observed mainly in the high risk population-that is, patients with five or more factors from the FRISC score. In these patients 10 lives and 10 non-fatal MI were saved for every 100 treated, a remarkably high number. Although only about $12 \%$ of the FRISC II population was considered to have high risk it is of vital importance to identify these patients. However, the reduction of the composite of death and MI was also seen in the large intermediate risk group. In contrast, there seemed to be no gain in the low risk population, where end point rates were low. Also, in the TACTICS trial, which as end point also included rehospitalisation for an acute coronary syndrome, the most beneficial effect was seen in those who, based on the TIMI score, were regarded as medium and high risk patients. ${ }^{3}$ In the TIMI IIIB trial, which used another risk score, death/MI was reduced in the high and very high risk patients, although the overall study did not reach significance. ${ }^{25}$

\section{Study limitations}

The FRISC study selected only patients with objective signs of myocardial ischaemia, thus mostly patients with medium and high risk. This study may not be fully applicable to low risk patients. In the majority of the patients of the present study the interleukin 6 concentration was used to indicate inflammatory activity. However, CRP determination is more generally available, which is a limitation of the study.

In the proposed score only factors present on admission are included. However, during the hospital stay other risk factors, such as the occurrence of ischaemic episodes with continuous ECG monitoring ${ }^{26}$ or the results of an exercise test, may modify the initial judgement. ${ }^{27}$

This risk score is based on a retrospective analysis of a previous study and should be confirmed in a prospective study. Furthermore, the study was confined to Scandinavian patients and few had prior revascularisation.

\section{Conclusions}

In unstable CAD, the FRISC score, based on the seven factors age $\geqslant 70$ years, male sex, diabetes, previous MI, ST depression on admission, and increased concentrations of troponins and interleukin 6 or CRP, is readily available and highly useful both for risk stratification and for selection of patients for an early invasive strategy. For patients with three or more of these factors an early invasive strategy is recommended, whereas for those with $0-2$ factors event rates are low regardless of strategy.

\section{ACKNOWLEDGEMENTS}

We gratefully acknowledge biostatisticians Johan Lindbäck and Niclas Eriksson at Uppsala Clinical Research Centre for their statistical advice.

\section{Authors' affiliations}

B Lagerqvist, E Diderholm, B Lindahl, L Wallentin, Department of Medical Sciences, Cardiology, University Hospital, Uppsala, Sweden S Husted, Department of Cardiology, University Hospital, Aarhus, Denmark

F Kontny, Department of Cardiology, Ullevål University Hospital, Oslo, Norway

E Ståhle, Department of Thoracic Surgery, University Hospital, Uppsala, Sweden

E Swahn, Department of Cardiology, University Hospital, Linköping, Sweden

P Venge, A Siegbahn, Department of Medical Sciences, Clinical Chemistry, Uppsala University, Uppsala, Sweden

Sources of support: The Pharmacia \& Upjohn Company and the Swedish Heart-Lung Foundation.

\section{REFERENCES}

1 FRISC II Investigators. Invasive compared with non-invasive treatment in unstable coronary- artery disease: FRISC II prospective randomised multicentre study. FRagmin and Fast Revascularisation during InStability in Coronary artery disease Investigators. Lancet 1999;354:708-15.

2 Wallentin L, Lagerqvist B, Husted S, et al. Outcome at 1 year after an invasive compared with a non-invasive strategy in unstable coronary-artery disease: the FRISC II invasive randomised trial. FRISC II Investigators. Fast revascularisation during instability in coronary artery disease. Lancet 2000;356:9-16.

3 Cannon CP, Weintraub WS, Demopoulos LA, et al. Comparison of early invasive and conservative strategies in patients with unstable coronary syndromes treated with the glycoprotein Ilb/Illa inhibitor tirofiban. NEngl J Med 2001;344: 1879-87.

4 Fox KA, Poole-Wilson PA, Henderson RA, et al. Interventional versus conservative treatment for patients with unstable angina or non-ST-elevation myocardial infarction: the British Heart Foundation RITA 3 randomised trial. Randomized intervention trial of unstable angina. Lancet 2002;360:743-51.

5 Savonitto S, Ardissino D, Granger CB, et al. Prognostic value of the admission electrocardiogram in acute coronary syndromes. JAMA 1999;281:707-13.

6 Diderholm E, Andren B, Frostfeldt G, et al. ST depression in ECG at entry indicates severe coronary lesions and large benefits of an early invasive treatment strategy in unstable coronary artery disease. The FRISC II ECG substudy. Eur Heart J 2002;23:41-9.

7 Ohman EM, Armstrong PW, Christenson RH, et al. Cardiac troponin T levels for risk stratification in acute myocardial ischemia. GUSTO IIA Investigators. N Engl J Med 1996;335:1333-41.

8 Heeschen C, Hamm CW, Goldmann B, et al. Troponin concentrations for stratification of patients with acute coronary syndromes in relation to 
therapeutic efficacy of tirofiban. PRISM Study Investigators. Platelet receptor inhibition in ischemic syndrome management. Lancet 1999;354:1757-62.

9 Diderholm E, Andren B, Frostfeldt G, et al. The prognostic and therapeutic implications of increased troponin T levels and ST depression in unstable coronary artery disease: the FRISC II invasive troponin T electrocardiogram substudy. Am Heart J 2002;143:760-7.

10 Heeschen C, Hamm CW, Bruemmer J, et al. Predictive value of C-reactive protein and troponin $\mathrm{T}$ in patients with unstable angina: a comparative analysis. CAPTURE Investigators. Chimeric C7E3 antiplatelet therapy in unstable angina refractory to standard treatment trial. J Am Coll Cardiol 2000;35:1535-42.

11 Lindahl B, Toss H, Siegbahn A, et al. Markers of myocardial damage and inflammation in relation to long-term mortality in unstable coronary artery disease. FRISC Study Group. Fragmin during instability in coronary artery disease. N Engl J Med 2000;343:1139-47.

12 Lindmark E, Diderholm E, Wallentin L, et al. Relationship between interleukin 6 and mortality in patients with unstable coronary artery disease: effects of an early invasive or noninvasive strategy. JAMA 2001;286:2107-13.

13 Jacobs DR Jr, Kroenke C, Crow R, et al. PREDICT: a simple risk score for clinical severity and long-term prognosis after hospitalization for acute myocardial infarction or unstable angina: the Minnesota heart survey. Circulation 1999; 100:599-607

14 Boersma E, Pieper KS, Steyerberg EW, et al. Predictors of outcome in patients with acute coronary syndromes without persistent ST-segment elevation: results from an international trial of 9461 patients. The PURSUIT Investigators. Circulation 2000;101:2557-67

15 Kennon S, Price CP, Mills PG, et al. Cumulative risk assessment in unstable angina: clinical, electrocardiographic, autonomic, and biochemical markers. Heart 2003:89:36-41.

16 Piombo AC, Gagliardi JA, Guetta J, et al. A new scoring system to stratify risk in unstable angina. BMC Cardiovasc Disord 2003;3:8.

17 Antman EM, Cohen M, Bernink PJ, et al. The TIMI risk score for unstable angina/non-ST elevation Ml: a method for prognostication and therapeutic decision making. JAMA 2000;284:835-42.
18 Sabatine MS, Januzzi JL, Snapinn S, et al. A risk score system for predicting adverse outcomes and magnitude of benefit with glycoprotein Ilb/llla inhibitor therapy in patients with unstable angina pectoris. Am J Cardiol 2001:88:488-92.

19 Austen WG, Edwards JE, Frye RL, et al. A reporting system on patients evaluated for coronary artery disease. Report of the Ad Hoc Committee for Grading of Coronary Artery Disease, Council on Cardiovascular Surgery, American Heart Association. Circulation 1975;51:5-40.

20 Venge $\mathbf{P}$, Lagerqvist $B$, Diderholm $E$, et al. Clinical performance of three cardiac troponin assays in patients with unstable coronary artery disease (a FRISC II substudy). Am J Cardiol 2002;89:1035-41.

21 Van Miltenburg-van Zijl AJ, Simoons ML, Veerhoek RJ, et al. Incidence and follow-up of Braunwald subgroups in unstable angina pectoris. J Am Coll Cardiol 1995; 25:1286-92.

22 Calvin JE, Klein LW, VandenBerg BJ, et al. Risk stratification in unstable angina: prospective validation of the Braunwald classification. JAMA 1995;273:136-41.

23 Yusuf S, Zucker D, Peduzzi P, et al. Effect of coronary artery bypass graft surgery on survival: overview of 10-year results from randomised trials by the coronary artery bypass graft surgery trialists collaboration. Lancet coronary artery bypas

24 Lagerqvist B, Safstrom K, Stahle E, et al. Is early invasive treatment of unstable coronary artery disease equally effective for both women and men? FRISC II Study Group Investigators. J Am Coll Cardiol 2001;38:41-8.

25 Solomon DH, Stone PH, Glynn RJ, et al. Use of risk stratification to identify patients with unstable angina likeliest to benefit from an invasive versus conservative management strategy. J Am Coll Cardiol 2001:38:969-76.

26 Jernberg T, Lindahl B, Wallentin L. ST-segment monitoring with continuous 12-lead ECG improves early risk stratification in patients with chest pain and ECG nondiagnostic of acute myocardial infarction. J Am Coll Cardiol 1999;34:1413-9.

27 Wilcox I, Freedman SB, Allman KC, et al. Prognostic significance of a predischarge exercise test in risk stratification after unstable angina pectoris. J Am Coll Cardiol 1991;18:677-83.

\section{IMAGES IN CARDIOLOGY}

\section{Prior CABG does not prevent pericardial tamponade following saphenous vein graft perforation associated with angioplasty}

7

his figure is an angiographic image of a right coronarysaphenous vein graft (SVG) perforation following "post-

dilatation" of a stent in the proximal graft. This rapidly led to pericardial tamponade requiring pericardial drainage and the deployment of a covered stent.

Vessel perforation following percutaneous coronary intervention is rare, occurring in $0.29-0.8 \%$ and is more often associated with atheroablative procedures. Progression to pericardial tamponade occurs in $31-46 \%$ of cases.

It is believed that prior coronary artery bypass graft surgery (CABG) protects against progression to tamponade because of the presence of pericardial adhesions and the persistence of a pericardiotomy. In addition, proximal SVG segments may be thought to be extra-pericardial in location. This may be a misconception with anatomy texts confirming that "the pericardium fuses with the great vessels superiorly and may include the ascending aorta".

Following surgery, the pericardium is sometimes repaired. This occurs more often when technically straightforward and in young patients where potential reoperation may be simplified if adhesions are minimised. This offers an appealing explanation but was not the case. More commonly the pericardium is left open forming a "pseudo-pericardial" space bounded by the pericardium laterally and posteriorly

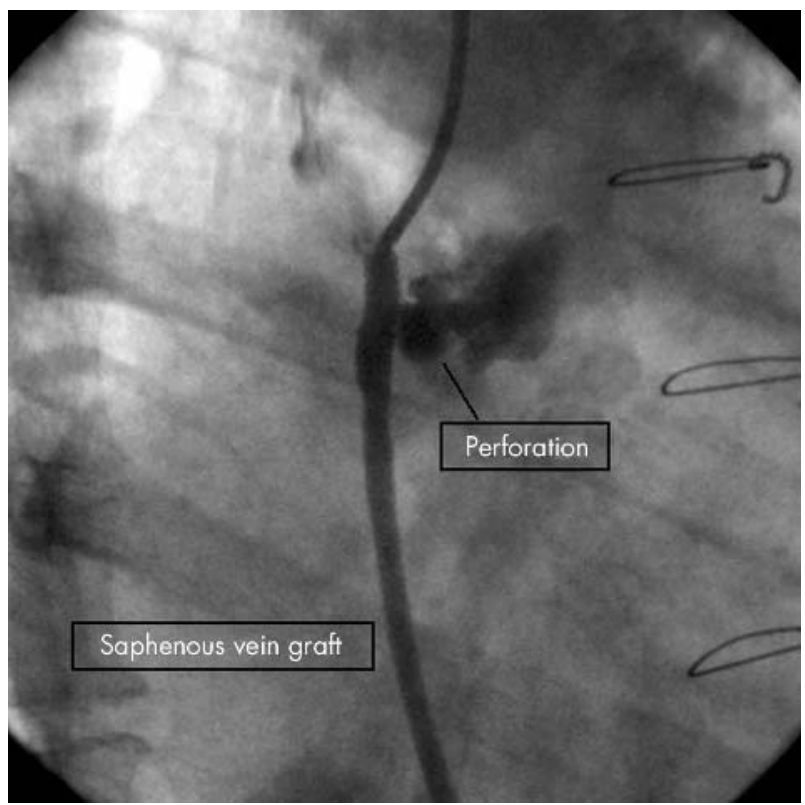
with the chest wall anterior. There is no mechanical boundary superiorly and this is the probable means by which extravasated blood was able to compress the cardiac chambers.

This case depicts a rare adverse outcome and makes the point that the mechanical effects of prior CABG do not eliminate the risk of tamponade following vessel perforation even in proximal SVG segments. 